\title{
The experience of cognitive impairment in critically ill patients in and beyond intensive care: findings from a larger phenomenological study
}

\author{
Agness C. Tembo
}

Correspondence: Agness.Tembo@newcastle.edu.au

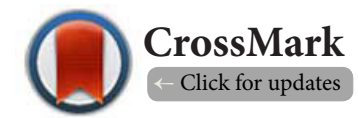

The University of Newcastle, Faculty of Health and Medicine, School of Nursing and Midwifery, Callaghan Campus, Newcastle NSW 2308, Australia.

\begin{abstract}
Background: Although Daily Sedation Interruption (DSI) is associated with better physical outcomes, many intensive care (ICU) survivors continue to suffer from cognitive impairment in and beyond ICU; neither has the meaning patients attach to the experience of cognitive impairment been extensively explored in the context of DSI.

Objective: To gain an understanding of and uncover the experience of critical illness in ICU and beyond in the context of DSI. To establish whether or not DSI improves the experience of critical illness in ICU and beyond.

Design: A hermeneutic phenomenological study using purposive sampling.

Setting: Single centre 16 bed ICU in a 500 bed regional tertiary referral Hospital in Australia.

Participants: Fifteen potential participants were approached. Two refused to participate, one died a week before the first interview, and 12 were enrolled into the study. Two participants withdrew from the study after the first interview, one was lost to follow-up and one was hospitalised. Inclusion criteria was patients aged 18 years and above who were mechanically ventilated and underwent DSI for at least 24 hours and were all able to speak English and give informed consent to participate in the study. Patients were excluded from the study if they had a poor prognosis, were less than 18 years old, unable to speak English, not ventilated and sedated for at least 24 hours.
\end{abstract}

Methods: Participants were interviewed using open ended questions at two weeks after discharge from ICU and at six to eleven months following the initial interview. Interviews were tape recorded, transcribed and thematically analysed by highlighting themes using a phenomenological approach.

Results: All the participants suffered some form of cognitive impairment resulting in the overarching theme of 'Being in Limbo' with three major themes of 'Being Disrupted', Being Imprisoned' and 'Being trapped'. The major themes 'Being Disrupted and 'Being Trapped' highlighted the prevalence of cognitive impairment.

Conclusion: Although DSI is associated with better physical ICU outcomes, it does not improve the experience of critical illness and it does not decrease the incidence of cognitive impairment in and beyond ICU. What is already known about the topic. Daily sedation interruption is associated with improved physical outcomes. Critical illness is associated with cognitive impairment. What this paper adds This research shows that despite DSI the experience of critical illness in ICU and beyond is that of being in limbo during and after critical illness. DSI does not decrease the incidence of cognitive impairment in ICU survivors.

Keywords: Intensive care unit, sleep deprivation, daily sedation interuption, critical illness, quality of life, survivorship

(C) 2015 Agness C. Tembo; licensee Herbert Publications Ltd. This is an Open Access article distributed under the terms of Creative Commons Attribution License (http://creativecommons.org/licenses/by/3.0). This permits unrestricted use, distribution, and reproduction in any medium, provided the original work is properly cited. 
Agness C. Tembo, Journal of Nursing 2015,

http://www.hoajonline.com/journals/pdf/2056-9157-2-1.pdf

doi: $10.7243 / 2056-9157-2-1$

\section{Background}

Cognitive Impairment is the inability to think, concentrate, formulate ideas, reason and remember [1]. It is distinct from a learning disability in so far as it may have been acquired later in life as a result of an accident or illness. It is a failure of a person to recognise their world [2]. For the purpose of this paper, cognitive impairment is defined as a major clinical decline in one or more functions of the brain, i.e., attention, memory executive function, intellectual function and mental processing speed including visual spatial abilities [1]. Classification of cognitive impairment can be mild, moderate or severe [3].The severity of cognitive impairment is subjective because it depends on the individual's baseline cognitive function [1]. However, the hallmark of cognitive decline is the extent to which it interferes with the individual's everyday life [1].

Cognitive impairment in ICU survivors has continued to increase [4]. At least one to three in four ICU survivors experience cognitive impairment [5]. In addition, 73-100\% of ICU survivors suffer from cognitive impairment similar to mild to moderate dementia on discharge from ICU, of which 46-78\% continue experiencing the phenomenon at one year and $25-47 \%$ at two years [6]. Eighty six percent of critical illness patients survive ICU. Of these, $12-43 \%$ suffer from anxiety, $28 \%$ depression and 5-6.4\% report having post-traumatic stress disorder (PTSD) related symptoms related [7]. These critical illness negative sequelae place an ever increasing burden on the survivors and their families who have to make life-style changes $[7,8]$ to cope with the burden of care. Additionally, there is a fiscal burden on the health care system [4,8]. Evidence suggests that the burden after a critical illness in ICU leads to poor health with some patients going into nursing homes and long-term acute/chronic illness facilities $[\mathbf{7 , 8}]$.

Cognitive impairment is closely linked to delirium [5]. Approximately $60-80 \%$ of ventilated patients suffer from delirium [9]. Despite the rising incidence of delirium, the condition is almost always overlooked [9] thus resulting in higher incidence of cognitive impairment as a long term complication of ICU hospitalisation. Most of the survivors have physical and psychological sequelae including cognitive impairment that continue to afflict them for most of their life after ICU $[4,7,8]$. Despite growing knowledge and concern about survivorship sequelae, there are only a few interventional studies that have examined cognitive impairment in ICU $[4, \mathbf{1 3}, \mathbf{1 6}]$ hence there are no established models of care that systematically address this issue, particularly in Australia [10].

Studies conducted after Kress et al's check seminal work in 2003 [11] have yielded varying results. While Kress et al's [11] study found no relationship between DSI and PTSD there was no incidence of PTSD, some studies $[12,13]$ with a focus on shorter and long term outcomes such as delirium and PTSD have similarly found no relationship between these conditions and DSI up to 12 months and other studies $[4,9]$ have found differing results. However, all these studies only provide anecdotal evidence.
Brummel et al's [4] study is noteworthy. Brummel et al's a feasibility study examined cognitive impairment in ICU survivors. In their ACT ICU trial, Brummel et al., randomized to three groups, usual care, physical rehabilitation, or cognitive rehabilitation including physical rehabilitation. The authors performed twicedaily cognitive rehabilitation sessions regarding orientation, memory, and attention exercises such as forward and reverse digit spans, matrix puzzles, letter-number sequences, pattern recognition with conscious patients. Patients with cognitive at discharge underwent a 12-week, in-home cognitive rehabilitation program. Their aim was to determine the feasibility of early and sustained cognitive rehabilitation paired with physical rehabilitation in patients who are critically ill from medical and surgical intensive care units. The primary outcome for Brummel et al's study was executive functioning at 3-months following hospital discharge as measured by the Tower Test, a psychometric tool evaluating executive abilities. Their secondary outcomes included global cognitive function, physical function and Health Related Quality of Life through assessing scores on: Katz's ADL, Functional Activities Questionnaire, AD8, Short-Informant Questionnaire of Cognitive Decline in the Elderly, Clinical Dementia Rating Scale, Timed Up \& Go test, Mini-Mental State Exam, Dysexecutive Questionnaire, Activities-Specific Balance Confidence Scale, Behavior Rating Inventory of Executive Function, Behaviour Pain Inventory, Trails A \& B test, Repeatable Battery for Assessment of Neuropsychological Status, General Employment Questionnaire, Beck Depression Inventory II, Post-traumatic stress checklist, Short Form 36, Canadian Study of Health and Aging and patient weight, and Tower Test score at 12 month follow-up. The authors tracked readmission to the hospital and admission to a nursing home or skilled rehabilitation facility as secondary outcomes during the 12-month follow-up period. The study duration comprised one year of enrolment and one year for study completion following enrolment of the final patient. Brummel et al., provide anecdotal evidence that early cognitive and physical rehabilitation can result in optimal outcomes in ICU survivors. While Brummel's study was small, it's findings are supported by other studies $[4,10,13-15]$. However, more of studies are needed to provide high level evidence based practice guidelines for better outcomes of ICU survivors.

The findings in these studies prove that despite increased survival rates, patients continue to suffer from the sequelae of critical illness and ICU hospitalisation for a long time. The fact that the sequelae is mostly related to delusional memories, depression and anxiety means that patients' experience of critical illness and ICU therapies has not improved. HRQoL assessment is another way of measuring cost effectiveness and benefit of ICU balanced against its economic and human costs $[7,8]$. Measurement of the effectiveness and benefits of ICU however, is subjective in this case because the care end point should be aimed at providing a holistic outcome for patients and their families that considers psychological outcomes. Although some steps have been made to in cooperate families in the care of 
critically ill patients by open visiting hours, regular meetings with families and follow-up visit when the patient is the step down unit [16], this is inadequate as evidenced by the increasing number of ICU survivors with cognitive impairment [5].

ICU hospitalisation transforms people's perception of the world. Reports about losing past memories of one's existence after critical illness and ICU hospitalisation are emerging $[13,17,18]$. Increasing survivorship from critical illness is placing a burden on the patients, families and the health care system [9]. After years of ICU follow-up clinics in the UK, there is anecdotal evidence that ICU follow-up clinics have been effective in the UK $[16,19]$.

\section{Methodology}

Issues related to lived experience are best explored using phenomenology because it is science that examines phenomena based on the actor's point of view and takes us back to the original experience [20]. Phenomenology was used to conduct this research to give meaning to the experience of cognitive impairment. Phenomenology as a methodology is different from traditional scientific research, such as empiricism or intellectualism, in that instead of dealing with measurement, generalisations, objectivity, replication and knowledge that must be uniformly true for all, phenomenology seeks to uncover the uniqueness, quality and significance of human experience as it is lived and perceived by individuals [20]. Essentially, it seeks to understand what it is to be human. Phenomenological research aims at transcending scientific understanding, conceptualisations and abstractions about the world by describing lived experience [20]. How this fit with the rest? Expand or remove.

\section{Methods}

\section{Research question}

The question was: How has DSI impacted on the long term outcomes of critical illness survivors?

\section{Aim}

The aim was to gain an understanding and uncover the nature of the critical illness experience in ICU and beyond in the context of DSI (Daily Sedation Interruption).

\section{Setting}

The study was conducted at a 16 bed regional tertiary referral hospital ICU in Australia.

\section{Ethical approval}

Ethical approval was sought and granted in December, 2007 Reference No: 07/12/12/5.07 by the Hunter New England Health Research Committee and the University of Newcastle's Human Research Ethics Committee.

\section{Inclusion and exclusion criteria}

Inclusion criteria was that patients had to be aged 18 years and over, were critically ill, mechanically ventilated and undergone daily sedation interruption for at least 48 hours, could read and speak English and were not cognitively impaired (patients were oriented with a Glasgow coma scale of 15). Pseudonyms were used to protect the participants' identity. Exclusion criteria was all patients who had pre-existing or new onset of cognitive impairment, patients less than 18 years of age, patients who did not undergo DSI, patients who were non English speaking/understanding, and patients with poor prognosis.

Potential participants were approached and informed about the study by a third party, i.e., the nursing unit manager of the ICU and senior nurses. Table 1 below summarises the demographic of the twelve participants who were enrolled into the study.

\section{Study drug administration}

All patients were sedated with midazolam. Analgesic agents used were morphine and fentanyl. The Glasgow coma scale (GCS) was used to assess the level of consciousness (LOC),

Table 1. Participant summary of demographic and other relevant data.

\begin{tabular}{lllll}
\hline Participant & Age & Diagnosis & Lomv & Los in ICU \\
\hline 001 & 76 Anterior & STEMI - myocardial infarction affecting the full thickness of the heart muscle & 27 & 36 \\
002 & 76 & Triple Vessel CABG for crescendo angina & 8 & 10 \\
003 & 34 & $\begin{array}{l}\text { Lower segment caesarean section for foetal distress with severe metabolic acidosis } \\
\text { due to hyperemesis gravidarum }\end{array}$ & 2 \\
& & Status epilepticus & 4 & 6 \\
004 & 23 & Post operatively following laparatomy for a volvulus/strangulation hernia & 2 & 3 \\
005 & 71 & Multi trauma following a motor vehicle accident & 4 & 6 \\
006 & 41 & Aorta bifemoral bypass complicated by graft thrombosis & 5 & 9 \\
007 & 65 & Ventricular fibrillation arrest and aspiration pneumonitis & 11 & 13 \\
008 & 60 & Thoracic and abdominal trauma & 5 & 6 \\
009 & 20 & Metabolic diabetic keto acidosis complicated by bilateral pneumonia & 5 & 6 \\
010 & 69 & Community acquired pneumonia associated & 3 & 4 \\
011 & 58 & Right haemothorax secondary to a leaking thoracic aortic aneurysm & 3 \\
012 & 69 & & 4 \\
\hline
\end{tabular}


aiming for a score of 9-10. The modified Ramsey sedation scale was used to measure the sedation score, targeting a score between +1-0 during the infusion and a score of 0 during DSI. Any patient who scored a sedation score of -1 to -2 was re-sedated at half the rate of the infusions before DSI and infusion rates titrated to a sedation score of $+1-0$ and a GCS of 9-10.

\section{Data collection}

Data were collected between 2008 and 2009. Participants were interviewed using open ended questions at two weeks after discharge from ICU and at six to eleven months following the initial interview. In-depth interviews were taped and transcribed. Thematic analysis was conducted using a phenomenological approach based on Merleau-Ponty (1962)'s existential phenomenology and van Manen (1990)'s six dynamic interplay activities.

\section{Results}

Fifteen patients aged between 20 and 76 years were approached, two refused to participate, one died before the first interview. Two patients refused to have a second interview, one was lost to follow-up and one could not be interviewed for second time because he was hospitalized. Figure 1 below shows the process of participant recruitment and participation.

The overarching theme of the study was 'Being in Limbo' with major themes of'Being Disrupted'Being imprisoned' and 'Being Trapped'. The themes 'Being Disrupted' and 'Being Trapped' are discussed in relation to cognitive impairment.

\section{Being disrupted}

Disruption for the people in this study was through dislocation from their familiar environment and unconsciousness which later affected their cognitive status. The people in this study all

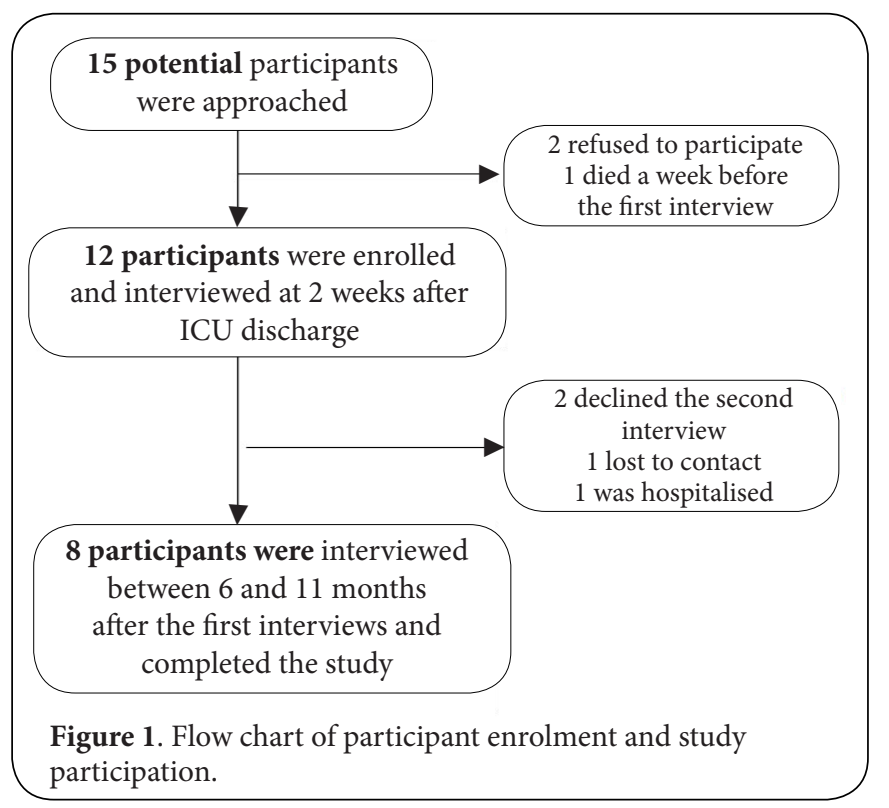

underwent a period of unconsciousness induced and regulated by ICU staff. Unconsciousness brought about existential and/ or biographical disruption, which was described in various ways-'being blacked out', 'being adrift', 'under the shadow of death'-and was followed by a period of 'trying to figure out' what had happened during the 'black out', later referred to as 'losing time' by some.

\section{Being blacked out too descriptive}

Patients referred to the period of unconsciousness as being blacked out because they did not know what happened to them. They lost touch with the world.

They tried to make sense of situations, reasoning and trying to figure out what had happened to them, knowing that their lives had been disrupted, that they had lost a sense of time, past events and continuity of existence. Heightening the sense of disruption was the devastatingly unfamiliar environment of ICU. Referring to the discovery of oneself in a strange environment, George said: 'I thought, where ... am I? ... Like I say, everything's clean and quiet it is, "where am I?" It was all foreign to me.'

In their reflections on being unconscious and having no awareness of the world, 'blank', and 'black' and 'silent' were words used to describe this experience. Participants described the absence of sound, time and feeling. The world, its objects and others were not known to them: they had lost the ability to commune with it. The ability to see and sense themselves and others was taken away from them. They described what it 'was like to lose time (life), as they reflected on their failure to know or remember what happened when they were unconscious. Some said it was perplexing:

I was bewildered ... I was blacked out, I don't remember anything ... I only thought I was ventilated for four hours for some reason, I don't know where that figure came from, but I was asleep for three days ... I didn't know what was going on and I didn't know how long I'd been there and I didn't know what was happening.

'Being blacked out' was marked by nothingness, as nothing was known and nothing remembered. There was no dreaming, no supernatural encounters and no sense of time. For most, there was only 'silence, darkness and blankness'. Many believed they should have had memories of their critical illness, or at least dreams or supernatural encounters, such as 'seeing bright lights, going to heaven', or other near-death experiences. One participant said:

I've heard people say they know when they're unconscious, but I didn't ... I thought I would have an experience where I would go to heaven ... but I didn't ... It was strange.'

Having no dreams was mystifying for some, as they realised how far removed from the world they had been. They described that 'visions' would have created memories of the 
time they were unconscious, and would have facilitated a continuous existence for them. Coming out of the darkness without dreams or visions was strange. Moira likened her experience to being in limbo without any dreams or visions, as she contrasted her previous experience of being operated on for cancer of the ribs with awakening in ICU:

[There were] no dreams, no going to heaven; that's strange, ... long time ago I had cancer and I was pregnant with my daughter and they'd found it was spreading up under my ribs and they said you'll have to wait until after the birth. So, just before I went into theatre my grandmother had passed away ... she came towards me at the end of the bed and said, 'You're going to be right, you'll be alright you'll see-you'll be alright it's not your time to come. And I got over that and ... I often think of that, I can remember that. So having had no super natural experience, it was just as if you were floating all of the time, lifeless, but no experience.

(Moira, $\mathbf{1}^{\text {st }}$ int.)

Keith was awestruck by being unaware that he was critically ill while unconscious:

It all just went blank ... I was out to it: absolute blank ... It was like black, blank. No dreaming, no nothing. No thoughts, no vision, no, not a thing. You'd think you would have, but not in my case, nothing ... you've got no recollection ... it was all just a mystifying blank. Until I was back in the land of the living you might say ... I was puzzled by it all.

(Keith, $1^{\text {st }}$ int.)

Another 'puzzling' thing for some was the inability to feel pain knowing very well that pain was inflicted on them, and that they should have felt pain from their illness or injury. They did not feel the touch of their loved ones nor hear people speaking over them. They did not know, nor could they remember, what happened to them. Their communication with the world was broken.

Hovering between consciousness and unconsciousness, participants described seeing obscure figures as if in a dreamlike state. Some patients talked of 'being out to it', others felt like they were 'floating', while others described having 'hallucinations', living in an unreal world. They were in a transitional state between wakefulness and unconsciousness, which could be likened to the theological definition of the word 'limbo' as a 'place between heaven and earth where good souls go to rest before finally entering heaven' (Word Power Dictionary, 2006, p. 560). They were adrift.

\section{Being adrift}

'Being adrift' describes patients' experiences of semi-consciousness or hallucination, and not having a complete hold on the world. Some patients experienced a sense of drifting between sleep and wakefulness, aware that their lives had been disrupted in some way. Being adrift created a sense of disorder in the patients' lives, so that they were unsure of where they were, whether they were dead or alive or somewhere in between. Perceptions of the world were distorted, as they hovered between states of consciousness and unconsciousness. They were distracted by sights, sounds and events that did not make sense to them, and an overwhelming sense of things not being right. Most could vaguely see what was going on around them as in a mirror or a dream. Their surroundings and people were distorted figures. George described being suspended between reality and unreality:

You know like ... you see those mirrors that are rounded and people look at them and your face distorts, I remember Chantelle [his daughter] coming to me and she got really close ... And then she did that a couple of times. Like it was strange [sic].

(George, $1^{\text {stint.) }}$

For most participants seeing people performing procedures on them and not being able to feel their touch, seeing people talking to and around them but not being able to hear them made them think something was terribly wrong. Some were confused. Jason said:

It is just a thing that you go in and you get a little or big conscious and you think, 'oh yes.' You are not actually aware of the whole surroundings [sic], you're only aware of whoever, or you don't even know whoever or whatever, but they're doing something for you and you're just a little bit aware of that and then you float off a bit, you know ... like I said, I didn't feel any pain, I didn't feel anything very much, you know, I was aware of people floating around doing things.

(Jason, $\mathbf{1}^{\text {stint. }}$ )

For Jason, the brief encounters of awareness helped him feel safe and cared for. He said:

When I was in the dream-like state ... I have memories of a nice lady who brushed my teeth for me. Every now and then there must have been someone there that did something for me when I came out and I thought, that's nice, but I felt so taken care of and safe.

(Jason, $\mathbf{1}^{\text {stint.) }}$

Being between the black out and the world was bewildering for some participants. They remembered hearing and seeing things that were not real. In contrast to Jason, they did not feel safe and cared for. Their hallucinations evoked feelings of uncertainty, doubt and ambiguity. Moira said:

I thought my lips were-that's what it felt like, that my lips were sewn up-they weren't, but I thought it was with red cotton, and why red, I don't know, but that's what I thought. And I had seen the nurse that was on and the doctor that I had seen when I was coming to and they frightened me 
Agness C. Tembo, Journal of Nursing 2015,

because I thought, 'they're the ones that have done this to me.' I must have been in a daze.

(Moira, $1^{\text {stint.) }}$

Monika's transitional state was marked by unbearable hallucinations:

And everything was red! I had red Zulus dancing for me in the [pause]_you know with their rings and their spears. They were dancing for me in the room. [Laughs timidly] Haha! Spiders and people peering in the glass ... I was mopping all the chip-bark off the red pavers and sticking the red mop in the corner with the other mops. I had a collection of about half a dozen mops in there and vacuum cleaners over here... and I'm thinking, what am I doing, I'm not cleaning, I'm in my bed... all the visions were red...I thought-I can't have this stuff no more.

(Monika, $1^{\text {stint.) }}$

Others experienced misperceptions of things and sounds. lan described his experience as follows:

All the red lights looked like Christmas trees or fairy lights. So I actually went back to thank the staff there a few weeks ago and I asked them to look at this thing so that I could see what it was and it was just red lights...I kept hearing what I thought was a baby goat... and I thought that they were slaughtering it... And I got the doctor and I said to her, 'tell them not to kill that goat.' And she said to me, 'there are no animals in this hospital.' I said, 'there's a baby goat in here.' It was a baby alright, but not a goat-a newborn child.

(Ian, $2^{\text {ndint. })}$

As patients regained consciousness and discharged home, they continued to reconnect with their ICU experience in vain while some discovered they could not remember their past.

\section{Being trapped in a body that cannot remember the past}

All the participants in this study could not remember what happened to them during their initial ICU hospitalisation. For some, the period was as long as five days. They referred to that period as lost time. Keith succinctly described this phenomenon as follows:

It is time stood still: don't remember the time I went in - time I woke up just seemed like five minutes, but it was weeks. And then the time... no recollection or knowledge of what hap pened, what transpired, nothing at all. It is all just a mystery, a mystifying blank, time lost.

(Keith $1^{\text {st Int.) }}$ Others described losing their memory and being unable to focus. Jason described his situation as follows:

Ilost; it seems a big part of my memory. I was very, very vague, you know.//.. I was like that, apart from that, I could not keep my mind on anything. I could not read a book and I'm a great reader, I could not even watch TV or anything because I could not keep my mind on anything, my mind seemed to be, like I was behind the eight-ball all of the time.

(Jason $1^{\text {st }}$ Int.)

Not remembering evoked feelings of horror for some participants and oneyoung participant. This is evidenced by Moira's account who could not remember her past including her name:

It is horrifying. So it's just strange what happens. Well you're born and you're given a name aren't you? And you've had that all your life. Some days, if someone knocked on the door and said to me, 'Moira, l'd look at them blank and think now, who's that? ... And it makes me so sad that [sobbing] — that they can remember the things and I can't. That is a horrible feeling.

(Moira $1^{\text {st }}$ Int.)

Not only did the participants experience horror by not remembering, they were frustrated. Maggie still hoped they could recover their memories.

I've lost memories, so it is frustrating but once l leave the hospital memories are going to be triggered and I'm going to continue living and I'm going to create new memories so, that's what is going to be important...

(Maggie $1^{\text {st }}$ Int.)

Others remembered the past but could not retain recent events or thought processes. They had become forgetful.

\section{Being trapped in a forgetful body}

Being forgetful affected mostof theparticipants. Both young and old were affected. Jason, one of the older participants, described this predicament as follows:

I can go from here to the shed and forget when I've got down there what I've gone down there for. Yeah it bothers me... because if I didn't have my own business but if I was working for someone that would not be very good [chuckle]. You know they say, 'Could you do so and so?' And you go, 'do you want to run that by me again?'

(Jason, $2^{\text {nd }}$ Int.)

Younger participants were worried by the prospect of living with a mind that was forgetful. Erick put it this way:

I used to keep appointments but I forget a lot of things now. I forget meetings I've got to go to. I just forget all about things I've got to do. It is scary to think that I can't keep appointments. I am worried.

(Erick $2^{\text {nd }}$ Int.)

Some participants were tormented by sleepless nights. There post ICU body could not sleep. 


\section{Being trapped in a body that cannot sleep}

Five participants could not sleep at night both in and beyond ICU. Most of them could not tell why they couldn't sleep. The situation they found themselves in left them distraught as Keith said:

And you just lay there all night - for the rest of the night. You knew what was going on around you all the time and think 'oh 1 o'clock, 2 o'clock, 3 o'clock, 4 o'clock all awake-hour after hour getting desperate to get a night's sleep. I don't know why. I'm still the same here. I can't sleep.

(Keith $1^{\text {st }}$ Int.)

But some participants attributed the sleeplessness to nightmares which were marked by relieving the ICU experience, causing them to be disoriented and frightened. Not knowing when the terror was going to end perpetuated anxiety and fear for them. One participant said:

They come in the dreams. Waking up with the tubes and being tied to the bed. I keep waking up, tossing and turning and get ting up through the night... I feel like I'm tied down and they've got tubes in my mouth... When it's real quiet I hear sounds of the monitors going off, beep and beep-beep. Starts to freak me out 'because I have the feeling of being back in hospital...I don't know when all this will end.

(Eric $2^{\text {nd }}$ Int.)

The narratives here highlight the nature of cognitive impairment, the various ways it manifested itself and the meaning the participants attached to it.

\section{Discussion}

Despite DSI this study demonstrates that both older and younger participants had difficulties remembering their thoughts, intentions and plans, while others had difficulties concentrating. For the older participants, age related changes and pathology such as dementia may have been implicated but there was no documented previous history of cognitive decline for them. It is therefore possible to surmise that DSI does not avert cognitive impairment. It is also possible that some elderly participants may have had undiagnosed onset of dementia which could have been triggered or exacerbated by critical illness and sedation and analgesic drugs that were used to keep them unconscious and to relieve pain. This argument is supported by earlier studies $[\mathbf{9 , 2 0 , 2 2 ]}$ that argued that elderly patients with post-operative delirium were more likely to have underlying dementia which could be triggered by anaesthetics and analgesics consistent with ICU-accelerated dementia [17] Pre- and post-operative cognitive function testing would have been beneficial in identifying patients with pre-existing cognitive problems like dementia and Alzheimer's disease $[21,23]$. However, that was not possible for this study given that critical illness almost always occurs as a sudden event. In addition, critical illness particularly sepsis, delirium, hypotension, hypoxia/hypoperfusion and direct inflammation can lead to brain injury that can consequently result in short and long-term cognitive decline [24].

Although memory loss is extensively documented, there is limited knowledge of its pathogenesis, brain dysfunction, protection and recovery [25]. In this study, two young participants reported cognitive difficulties even though it could be argued that an association with sleep deprivation and the underlying condition of epilepsy was most likely. However, the incidence of cognitive impairment in both young and elderly participants implies that there is a greater problem than dementia that must be investigated. Furthermore, increasing data on cognitive impairment $[\mathbf{9}, \mathbf{1 3}, \mathbf{2 6 - 2 9}]$ underscores the immediacy with which it should be addressed. It is therefore imperative that although elderly people are more susceptible to cognitive impairment because of their physiological status, younger people ( $<65$ years) should be assessed as they are equally susceptible [6] This study's finding of elderly participants who suffered VF arrest and experienced cognitive impairment confirmed anecdotal evidence that VF arrest is associated with cognitive impairment due to cerebral hypoxia resulting from hypotension, decreased blood flow and oxygen delivery to the brain $[4,17]$.

Advanced technology and improved practices in ICU have led to people living longer and surviving critical illness and ICU hospitalisation. However, survivorship can be problematic becauseas demonstrated in this study, survivors continue to suffer from the sequelae of critical illness and ICU treatment [29-34] particularly in the older population who may develop functional and cognitive disabilities following ICU discharge $[22,32]$. Despite increasing data, post critical illness sequalae remains under recognized [22] as an integral aspect of critical illness. Of concern is that unlike the participants in this study, patients are generally unable to legitimise the ongoing consequences of their critical illness. The few strategies (ICU diaries and rehabilitation clinics [34] that have been set up need tobe more extensively implemented worldwide. Increasing awareness of the magnitude of cognitive impairment in ICU survivors and the attempts to establish follow-up for critical illness survivors are recommended. This necessitates continued increased awareness among ICU practitioners and the need for models of care like those of stroke and cancer patients $[4,8]$.

\section{Strengths and limitations of the study}

The limitation of this study lies in the fact that it was conducted in a single centre setting. The sample size though small is consistent with a qualitative study seeking to explore the experience of critical illness in ICU and beyond. The strength of the study is its elucidation of continued suffering of critical illness survivors due to cognitive impairment; revealing the need for more attention to research and clinical practice that continues to explore treatments and strategies of improving 
Agness C. Tembo, Journal of Nursing 2015,

http://www.hoajonline.com/journals/pdf/2056-9157-2-1.pdf

doi: $10.7243 / 2056-9157-2-1$

patients' HQoL during and after ICU.

\section{Research implications}

Research into strategies that can prevent or reduce the incidence of cognitive impairment in ICU survivors will be beneficial.

Research into effectiveness of follow-up clinics for ICU survivors would be helpful.

Identification of predisposing factors for cognitive impairment will inform clinical practice and reduce the incidence of cognitive impairment.

\section{Clinical implications}

Early goal directed assessment for, identification, treatment and prevention of risk factors for cognitive impairment in and beyond ICU is needed.

Continued multidisciplinary support and monitoring of ICU survivors is essential.

Despite the anecdotal evidence, ICU follow-up clinics are a worthwhile approach to continued support and treatment of ICU survivors with cognitive impairment.

\section{Competing interests}

The author declares that she has no competing interests.

Acknowledgement

The author extends acknowledgments to Conjoint Professor Isabel Higgins (University of Newcastle, NSW, Australia) and Professor Vicki Parker (University of New England, NSW Australia) for supervising the research process.

\section{Publication history}

Editor: Jean Ivey, The University of Alabama, USA.

Received: 20-Jul-2015 Final Revised: 07-Sep-2015

Accepted: 21-Sep-2015 Published: 28-Sep-2015

\section{References}

1. Hopkins RO and Brett $S$. Chronic neurocognitive effects of critical illness. Curr Opin Crit Care. 2005; 11:369-75. | Article | PubMed

2. Folstein M, Anthony JC, Parhad I, Duffy B and Gruenberg EM. The meaning of cognitive impairment in the elderly. J Am Geriatr Soc. 1985; 33:228-35. | Article | PubMed

3. Brummel NE, Girard TD, Ely EW, Pandharipande PP, Morandi A, Hughes CG, Graves AJ, Shintani A, Murphy E, Work B, Pun BT, Boehm L, Gill TM, Dittus RS and Jackson JC. Feasibility and safety of early combined cognitive and physical therapy for critically ill medical and surgical patients: the Activity and Cognitive Therapy in ICU (ACT-ICU) trial. Intensive Care Med. 2014; 40:370-9. | Article | PubMed Abstract | PubMed Full Text

4. Needham DM, Feldman DR and Kho ME. The functional costs of ICU survivorship. Collaborating to improve post-ICU disability. Am J Respir Crit Care Med. 2011; 183:962-4. | Article | PubMed

5. Pandharipande PP, Girard TD, Jackson JC, Morandi A, Thompson JL, Pun BT, Brummel NE, Hughes CG, Vasilevskis EE, Shintani AK, Moons KG, Geevarghese SK, Canonico A, Hopkins RO, Bernard GR, Dittus RS and Ely EW. Long-term cognitive impairment after critical illness. N Engl J Med. 2013; 369:1306-16. | Article | PubMed Abstract | PubMed Full Text

6. Gordon SM, Jackson JC, Ely EW, Burger C and Hopkins RO. Clinical identification of cognitive impairment in ICU survivors: insights for intensivists. Intensive Care Med. 2004; 30:1997-2008. | Article | PubMed
7. Mikkelsen ME, Christie JD, Lanken PN, Biester RC, Thompson BT, Bellamy SL, Localio AR, Demissie E, Hopkins RO and Angus DC. The adult respiratory distress syndrome cognitive outcomes study: long-term neuropsychological function in survivors of acute lung injury. $\mathrm{Am} \mathrm{J}$ Respir Crit Care Med. 2012; 185:1307-15. | Article | PubMed Abstract | PubMed Full Text

8. Desai SV, Law TJ and Needham DM. Long-term complications of critical care. Crit Care Med. 2011; 39:371-9. | Article | PubMed

9. Elliott D, McKinley S, Alison J, Aitken LM, King M, Leslie GD, Kenny P, Taylor P, Foley R and Burmeister E. Health-related quality of life and physical recovery after a critical illness: a multi-centre randomised controlled trial of a home-based physical rehabilitation program. Crit Care. 2011; 15:R142. | Article | PubMed Abstract | PubMed Full Text

10. Mendelsohn $A B$ and Chelluri L. Interviews with intensive care unit survivors: assessing post-intensive care quality of life and patients' preferences regarding intensive care and mechanical ventilation. Crit Care Med. 2003; 31:S400-6. | Article | PubMed

11. Kress JP, Gehlbach B, Lacy M, Pliskin N, Pohlman AS and Hall JB. The longterm psychological effects of daily sedative interruption on critically ill patients. Am J Respir Crit Care Med. 2003; 168:1457-61. | Article | PubMed

12. Xing XZ, Gao Y, Wang HJ, Qu SN, Huang CL, Zhang H, Wang H, Xiao QL and Sun KL. Effect of sedation on short-term and long-term outcomes of critically ill patients with acute respiratory insufficiency. World J Emerg Med. 2015; 6:147-52. | Article | PubMed Abstract | PubMed Full Text

13 Jackson J.C, Pandharipande P.P, Girard T.D, Brummel N.E and Thompson J.L et al. Depression, Posttraumatic Stress Disorder, and Functional Disability in Survivors of Critical Illness: results from the BRAIN ICU (Bringing to light the Risk Factors And Incidence of Neuropsychological dysfunction in ICU survivors) Investigation: A Longitudinal Cohort Study. Lancet Respiratory Medicine. 2014; 2:369-379. I Article

14 Capuzzo M, Bertacchini S, Davanzo E, Felisatti G, Paparella L, Tadini L and Alvisi R. Health-related quality of life before planned admission to intensive care: memory over three and six months. Health Qual Life Outcomes. 2010; 8:103. | Article | PubMed Abstract | PubMed Full Text

15 Ringdal M, Plos K, Ortenwall P and Bergbom I. Memories and healthrelated quality of life after intensive care: a follow-up study. Crit Care Med. 2010; 38:38-44. | Article | PubMed

16 Jones C, Skirrow P, Griffiths RD, Humphris GH, Ingleby S, Eddleston J, Waldmann C and Gager M. Rehabilitation after critical illness: a randomized, controlled trial. Crit Care Med. 2003; 31:2456-61. | Article I PubMed

17 Khan J.M, Benson N.M, Appleby D, Carson S.S and Iwashyna T.J. Longterm acute care hospital utilisation after critical illness. Journal of the American Medical Association. 2010; 303:2253-2259. | Article

18 Iwashyna TJ, Ely EW, Smith DM and Langa KM. Long-term cognitive impairment and functional disability among survivors of severe sepsis. JAMA. 2010; 304:1787-94. | Article | PubMed Abstract | PubMed Full $\underline{\text { Text }}$

19 Modrykamien AM. The ICU follow-up clinic: a new paradigm for intensivists. Respir Care. 2012; 57:764-72. | Article | PubMed

20 vanManen M. Researching Lived Experience. Human science for an Action Sensitive Pedagogy. London, State University of New York. 1990.

21 Milbrandt EB, Eldadah B, Nayfield S, Hadley E and Angus DC. Toward an integrated research agenda for critical illness in aging. Am J Respir Crit Care Med. 2010; 182:995-1003. | Article | PubMed Abstract | PubMed Full Text

22 Ballard N, Robley L, Barrett D, Fraser D and Mendoza I. Patients' recollections of therapeutic paralysis in the intensive care unit. Am J Crit Care. 2006; 15:86-94. | Article | PubMed

23 Ehlenbach WJ, Hough CL, Crane PK, Haneuse SJ, Carson SS, Curtis JR and Larson EB. Association between acute care and critical illness hospitalization and cognitive function in older adults. JAMA. 2010; 303:763-70. | Article | PubMed Abstract | PubMed Full Text

24 Kapfhammer HP, Rothenhausler HB, Krauseneck T, Stoll C and Schelling G. Posttraumatic stress disorder and health-related quality of life in long- 
Agness C. Tembo, Journal of Nursing 2015,

http://www.hoajonline.com/journals/pdf/2056-9157-2-1.pdf

term survivors of acute respiratory distress syndrome. Am J Psychiatry. 2004; 161:45-52. | Article | PubMed

25 Karlsson $V$ and Forsberg A. Health is yearning--experiences of being conscious during ventilator treatment in a critical care unit. Intensive Crit Care Nurs. 2008; 24:41-50. | Article | PubMed

26 Lof L, Berggren L and Ahlstrom G. ICU patients' recall of emotional reactions in the trajectory from falling critically ill to hospital discharge: follow-ups after 3 and 12 months. Intensive Crit Care Nurs. 2008; 24:10821. | Article | PubMed

27 Parker V. Confronting Life and Death: Living through Critical Illness and Intensive Care Hospitalisation. Faculty of Health. Newcastle, The University of Newcastle. Masters Degree. 1997.

28 Roberts BL, Rickard CM, Rajbhandari D and Reynolds P. Patients' dreams in ICU: recall at two years post discharge and comparison to delirium status during ICU admission. A multicentre cohort study. Intensive Crit Care Nurs. 2006; 22:264-73. | Article | PubMed

29 Samuelson K, Lundberg D and Fridlund B. Memory in relation to depth of sedation in adult mechanically ventilated intensive care patients. Intensive Care Med. 2006; 32:660-7. I Article I PubMed

30 Needham DM, Dennison CR, Dowdy DW, Mendez-Tellez PA, Ciesla N, Desai SV et al. Study protocol: The Improving Care of Acute Lung Injury Patients (ICAP) study. 2005.| Article

31 Elliott D, Mudaliar Y and Kim C. Examining discharge outcomes and health status of critically ill patients: some practical considerations. Intensive Crit Care Nurs. 2004; 20:366-77. | Article | PubMed

32 Jackson JC, Girard TD, Gordon SM, Thompson JL, Shintani AK, Thomason JW, Pun BT, Canonico AE, Dunn JG, Bernard GR, Dittus RS and Ely EW. Long-term cognitive and psychological outcomes in the awakening and breathing controlled trial. Am J Respir Crit Care Med. 2010; 182:183-91. | Article | PubMed Abstract | PubMed Full Text

33 Beraldo PS. Rehabilitation in patients admitted to intensive care. $B M J$. 2009; 339:b3921. | Article | PubMed

34 Cuthbertson BH, Rattray J, Campbell MK, Gager M, Roughton S, Smith A, Hull A, Breeman S, Norrie J, Jenkinson D, Hernandez R, Johnston $M$ Wilson E and Waldmann C. The PRaCTICaL study of nurse led, intensive care follow-up programmes for improving long term outcomes from critical illness: a pragmatic randomised controlled trial. BMJ. 2009; 339:b3723. | Article | PubMed Abstract | PubMed Full Text

\section{Citation:}

Tembo AC. The experience of cognitive impairment in critically ill patients in and beyond intensive care: findings from a larger phenomenological study. J Nurs. 2015; 2:1. http://dx.doi.org/10.7243/2056-9157-2-1 